\title{
Role of S-layer proteins in bacteria
}

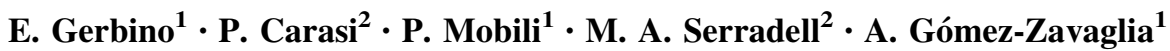

Received: 17 August 2015/ Accepted: 21 September 2015

(C) Springer Science+Business Media Dordrecht 2015

\begin{abstract}
S-layers are paracrystalline bidimensional arrays of proteins or glycoproteins that overlay the cell surface of several genus and species of bacteria and archaea. As the outermost layer of several genus and species of microorganisms, S-layer proteins (SLP) are in direct contact with bacterial environment and thus may be involved in many of their surface properties, including adherence to various substrates, mucins and eukaryotic cells, aggregation and coaggregation with yeasts and other bacteria. In addition, SLP have been reported to be responsible for the bacterial protection against detrimental environmental conditions and to play an important role in surface recognition or as carriers of virulence factors. In this mini-review, we bring together the latest evidences about functional and mechanical properties of bacterial SLP from two different perspectives: (A) their role on bacterial adherence to different substrates and surfaces, and (B) their role as mechanical barriers in bacterial harmful environments.
\end{abstract}

Keywords S-layer proteins - Adhesion - Aggregation · Biofilm formation - Interaction with the immune system . Resistance to adverse environmental conditions

A. Gómez-Zavaglia

angoza@qui.uc.pt

1 Center for Research and Development in Food Cryotechnology (CIDCA) CCT-CONICET La Plata, Calle 47 y 116, 1900 La Plata, Buenos Aires, Argentina

2 Laboratorio de Microbiología, Departamento de Ciencias Biológicas, Facultad de Ciencias Exactas, Universidad Nacional de La Plata, La Plata, Argentina

\section{Introduction}

S-layers are paracrystalline bidimensional arrays that overlay the cell surface of several gram-positive, gram negative bacterial species and archaea (Fig. 1a). They are composed of identical protein or glycoprotein subunits forming regular and highly porous arrays with oblique ( $\mathrm{p} 1$, $\mathrm{p} 2)$, square (p4) or hexagonal (p3, p6) symmetry and fully covering the microorganism during all stages of growth (Sleytr et al. 2001).

The interaction among S-layer protein (SLP) subunits with the underlying cell surface occurs through non-covalent forces. The protein subunits are typically rich in acidic and hydrophobic amino acids but poor in sulphur-containing amino acids, and in general have low overall isoelectric points (Sara and Sleytr 2000). SLP genes are highly expressed, but there is a low overall sequence similarity among them and no universal signature sequence. For this reason, confirmation of the presence of SLP still relies largely on electron microscopy.

Although in recent decades great amount of information about the biological role of SLPs has been accumulated, no common function between microorganisms has emerged. SLPs have been proven to be essential for the determination or maintenance of cell shape and functions as molecular sieves (Sleytr and Beveridge 1999), degradative enzymes (Calabi et al. 2001; Ahn et al. 2006; Prado Acosta et al. 2008), binding scaffold for large molecules, ions (Gerbino et al. 2015) or bacteriophages (Callegari et al. 1998) and mediators for bacterial adhesion (Sakakibara et al. 2007; Hynönen and Palva 2013; Shimotahira et al. 2013; Zhang et al. 2013). SLP also contribute to microorganisms pathogenicity through several mechanisms such as adhesion to hosts cells, extracellular matrix components and coaggregation with other microorganisms (Sakakibara 
A

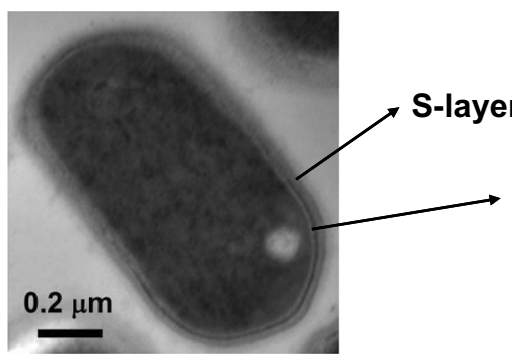

S-layer protein

Cell wall

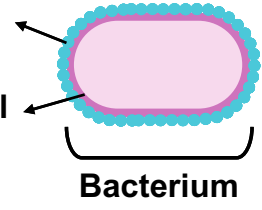

B

C

Adhesion to

epithelial

Coaggregation Autoaggregation
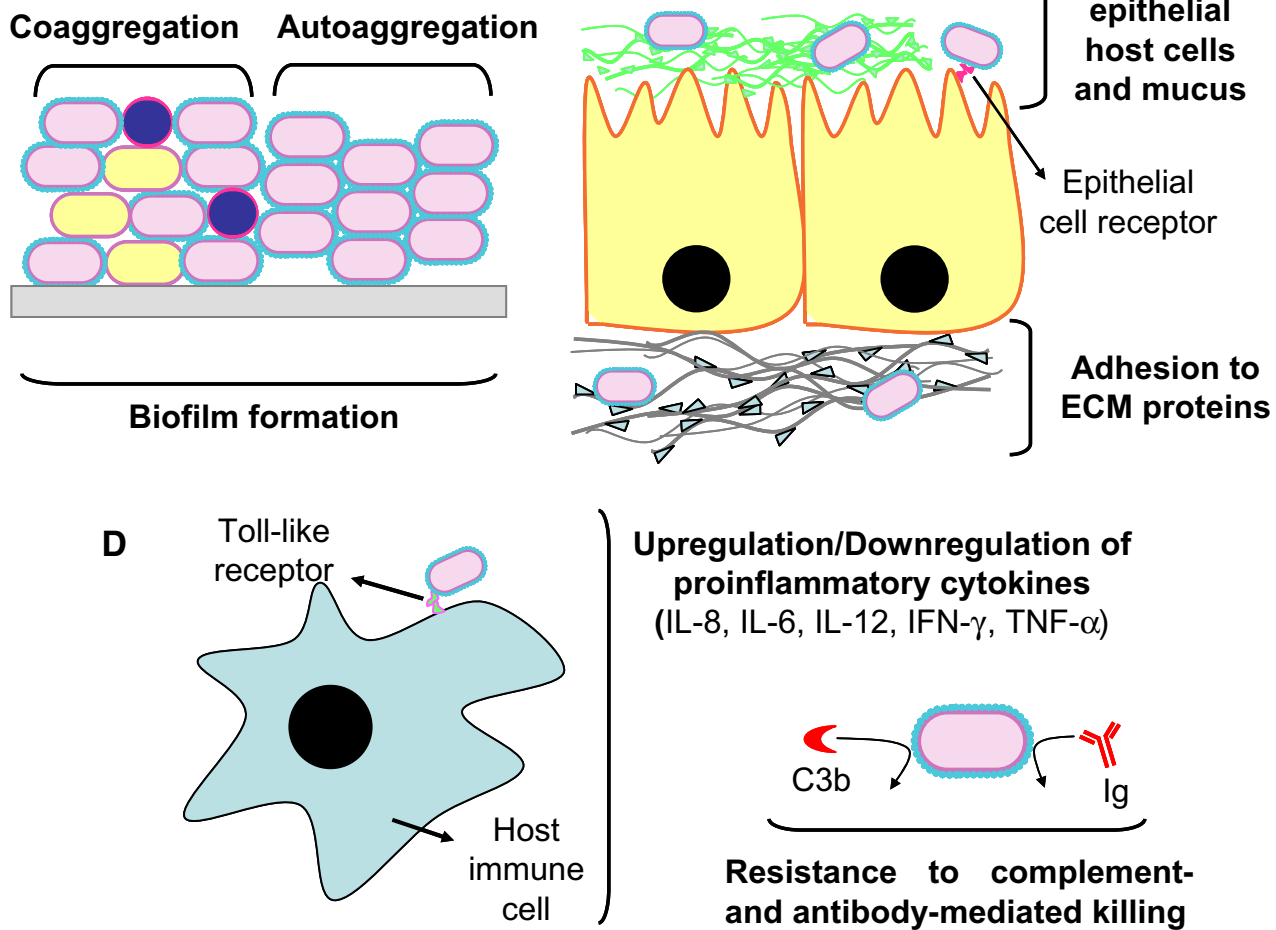

Upregulation/Downregulation of
proinflammatory cytokines
(IL-8, IL-6, IL-12, IFN- $\gamma$, TNF- $\alpha$ )

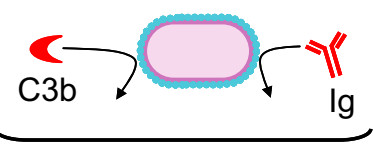

Resistance to complementand antibody-mediated killing

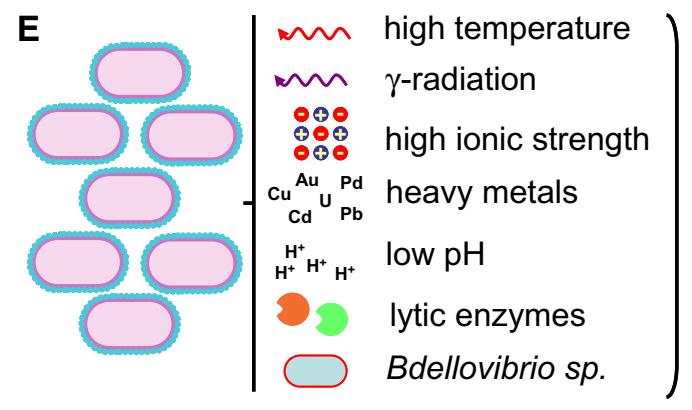

\section{Resistance to adverse environmental conditions}

Fig. 1 a Scanning electron micrography $(60,000 \times)$ and scheme showing S-layer proteins (SLP) forming the outermost layer in bacterial cell. b-e Some of the main functions ascribed to S-layer proteins in different bacterial species. SLPs play roles in bacterial adherence to different substrates and surfaces, and have been linked to the auto-aggregation ability, co-aggregation with other microorganisms and biofilm formation on biotic and abiotic surfaces (b); SLPs have also shown to mediate adhesion to mammalian gut epithelial cells, to different cell lines (such as Caco-2, HeLa and Hep-2 cells), to mucus and to different components of the extracellular matrix (ECM) such as laminin, fibronectin and collagen (c). SLPs from both pathogenic and non-pathogenic microorganisms have been involved in the interaction of bacteria with host immune system: interaction of SLP with toll-like receptors (TLR2 and TLR4) has been shown to be responsible for modulation of the pattern of cytokines released by monocytes, macrophages and dendritic cells, while the protective role of SLPs against humoral defenses such as complement and antibodies, has been shown to contribute to the pathogenicity of some microorganisms (d). SLPs also act as mechanical barriers that stabilize and protect bacteria in harmful environments, contributing to their resistance to gastrointestinal conditions (i.e., low $\mathrm{pH}$, proteolytic enzymes), to extreme environmental conditions (i.e., such as high temperatures, gamma radiation, high ionic strength and heavy metals), and even to provide resistance to predation by Bdellovibrio bacteriovorans in some species (e) 
et al. 2007; Hynönen and Palva 2013; Shimotahira et al. 2013; Zhang et al. 2013), biofilm formation (Dapa et al. 2013), and evasion of the host́s immune response via modulation of $\mathrm{T}$-cell responses, antigenic variation and protection from complement-mediated killing and phagocytosis (Thompson 2002; Ausiello et al. 2006; Ryan et al. 2011; Settem et al. 2013; Taverniti et al. 2013). Moreover, SLPs protect bacterial cells from environmental harmful factors including changes in environmental $\mathrm{pH}$ and mechanical and osmotic stresses (Engelhardt and Peters 1998; Gilmour et al. 2000; Claus et al. 2002; Engelhardt 2007), antimicrobial peptides or bacteriolytic enzymes (Lortal et al. 1992), radiation (Kotiranta et al. 1999) and bacteriophages and other microbial predators (Koval and Hynes 1991).

As outermost layers of several genus and species of microorganisms, SLPs are in direct contact with the environment. Therefore, their role can be addressed from two different perspectives:

(A) their role on bacterial adherence to different substrates and surfaces,

(B) their role as mechanical barriers in bacterial harmful environments.

In this minireview we will follow this approach to bring together the latest evidences about functional and mechanical properties of bacterial SLPs.

\section{Role of SLP on bacterial adherence to different substrates and surfaces}

Aggregation and adhesion are complex processes involving several molecules present on the cell wall surface of bacteria [i.e., teichoic and lipoteichichoic acids, (glyco)proteins] (Li et al. 2015). Several authors reported the role of SLPs in the bacterial capacity to auto- or coaggregate, and to adhere to several matrices, including gastrointestinal mucins, extracellular matrix macromolecules and epithelial cells (Sakakibara et al. 2007; Hynönen and Palva 2013; Shimotahira et al. 2013; Zhang et al. 2013).

\section{Autoaggregation and coaggregation with other microorganisms}

Autoaggregation represents a mechanism by which gastrointestinal commensals adhere to each other (Fig. 1b) and it could allow them to colonize persistently in biofilms on the host's mucosa (Turroni et al. 2013). Therefore, the involvement of SLP in this process has been particularly studied for bacterial strains with potentiality as probiotics. In fact, the removal of SLP with $5 \mathrm{M} \mathrm{LiCl}$ reduces the autoaggregation ability of different lactobacilli such as Lactobacillus acidophilus ATCC 4356 (Kos et al. 2003), L. kefiri CIDCA 8321 (Garrote et al. 2004) and L. helveticus M92 (Beganović et al. 2011). However, the strong autoaggregating phenotype of $L$. crispatus ZJ001 could be related to other cell surface components than SLP, since it is not markedly affected by treatment with $\mathrm{LiCl}$ (Chen et al. 2007).

The ability to aggregate with other microorganisms (coaggregation) (Fig. 1b) could be seen as a part of competitive exclusion mechanism which contribute to the reduction of the pathogenic load during infections. The role of SLP in the interaction with Salmonella Typhimurium FP1 has been demonstrated for L. helveticus M92 (Beganović et al. 2011) since their removal produces a decrease in coaggregation with this pathogen. On the other hand, SLP from aggregative L. kefiri strains mediates coaggregation with Saccharomyces lypolitica, interaction that may contribute to the maintenance of structure and composition of a complex microbial ecosystem as the kefir grain (Golowczyc et al. 2009).

\section{Adhesion to epithelial cells, gastrointestinal mucus and extracellular matrix macromolecules}

Microbial adhesion to epithelial and subepithelial tissue is an important initial step in successful colonization of the mammalian intestine and other tissue sites (Fig. 1c). Several adhesion molecules have been extensively characterized for potentially probiotic bacteria and for human or animal pathogens as well. Regarding the role of SLP in adhesion processes involving pathogenic and non-pathogenic bacteria, the results depend on both the substrate and the strain. Removal of S-layer from L. acidophilus M92 reduced bacterial adhesion to pig intestinal epithelium (Kos et al. 2003) and mouse ileal epithelial cells (Frece et al. 2005), meanwhile adhesion to Caco- 2 cells was not altered by LiCl-extraction of SLP from L. acidophilus BG2FO4 or NCFM/N2 (Greene and Klaenhammer 1994). On the other hand, SlpA of L. brevis ATCC 8287 possess affinity to human intestinal epithelial cell lines (Caco-2 and Intestine 407), urinary bladder (T24), endothelial cells (EA-hy926), since adhesion is abolished by guanidine-hydrochloride SLP-extraction (Hynönen et al. 2002). Besides, blockade of bacteria-cell interaction using anti-SLP specific antibodies demonstrated the involvement of SLP in the adhesion of $L$. crispatus ZJ001 to HeLa cells (Chen et al. 2007) and that of Clostridium difficile to Hep-2 cells (Calabi et al. 2002). In Bacillus cereus, the presence of SLP was correlated with the adhesion to epithelial HeLa cells and neutrophiles (Kotiranta et al. 1998; Auger et al. 2009).

Hynönen et al. (2002) used an interesting approach to assess the role of SlpA of L. brevis ATCC 8287 on adherence. Different regions of the $\operatorname{slpA}$ gene were expressed as internal in-frame fusions in the variable 
region of the $\mathrm{AlCH} 7$ gene of Escherichia coli. Chimeric flagella harbouring inserts that represented the N-terminal part of the SLP bound to different human epithelial cell lines as well as fibronectin, whereas the $\mathrm{C}$-terminal part of the SLP did not confer binding on the flagella. In a similar way, Åvall-Jääskeläinen et al. (2003) constructed a surface cassette display on the basis of SlpA receptor-binding domain, which was expressed in Lactococcus lactis NZ9000. In vitro adhesion assays indicated that the recombinant lactococcal cells had gained an ability to adhere to the cell line Intestine 407 and to fibronectin, mainly mediated by the $\mathrm{N}$ terminus-encoding part of the slpA gene.

Among non-mammal bacterial strains, the SlpA of the honey bee pathogen Paenibacillus larvae mediates adhesion to larval midgut cells, a key early step in the colonization of the bee gut by the pathogen (Poppinga et al. 2012).

The ability to adhere to extracellular matrix proteins such as collagen, laminin, fibronectin, or fibrinogen has been extensively studied for different strains of lactobacilli since it might have an important role in the displacement and competition with pathogens (Muñoz-Provencio et al. 2009). Several L. crispatus strains have been studied and the SLP domains responsible for adherence to collagen, characterized (Toba et al. 1995; Sillanpaa et al. 2000; Sun et al. 2013). Horie et al. (2002) demonstrated the ability of the L. crispatus CbsA SLP to inhibit adherence of an enterotoxic $E$. coli strain to laminin. Using surface plasmon resonance, de Leeuw et al. (2006) found that SlpA of $L$. brevis ATCC 8287 adhered with a higher affinity to fibronectin and laminin than to collagen. Similar results were obtained by Jakava-Viljanen and Palva (2007) with SLP-carrying lactobacilli isolated from porcine intestine and feces, using a different experimental approach.

Although adhesion of microorganisms to the mucus layer coating the gastrointestinal tract is the first step for them to interact with mammalian host cells (van Tassell and Miller 2011), the scarce number of papers dealing with this issue puts into relevance a quite large gap that requires to be filled (Fig. 1c). In this regard, the presence of mucin binding domains in SLPs has only been described for $L$. acidophilus NCFM (Buck et al. 2005). In turn, Sánchez et al. (2009) reported preliminary results regarding the interaction of $B$. cereus' SLPs with commercial porcine gastric mucins. Recently, Carasi et al. (2014) reported that L. kefiri strains treated with $\mathrm{NaOH}$ and $\mathrm{LiCl}$ have a lower capacity to adhere to porcine gastric mucin and mucus components extracted from piglet small intestine and colon. Moreover, the addition of soluble SLPs increased $L$. kefiri adhesion to these substrates, suggesting that the presence of these proteins in the gastrointestinal tract could enhance the bacterial adhesion to mucus layer, improving the interaction with the epithelium (Carasi et al. 2014). Since differences in the adhesion ability of $L$. kefiri strains to mucus and enterocytes were observed after in vitro simulation of gastrointestinal tract conditions $(\mathrm{pH}$, biliar salts and enzymes) we are currently investigating the role of SLP in this phenomenon.

\section{Biofilm formation}

In nature, bacteria exist mostly as biofilms, forming surface-associated microbial communities of interacting species. Bacteria in a biofilm are more resistant than their planktonic counterparts to different environmental stresses such as antimicrobial agents and host defenses (Marsh et al. 2011). In a bacterial biofilm, cells are associated with each other and/or attached to a surface and embedded in a selfproduced matrix of exopolymeric substances, including a variety of exopolysaccharides, (glyco)proteins, (glyco)lipids, and extracellular DNA (Flemming and Wingender 2010).

The preferred bacterial lifestyle (planktonic or biofilm) is highly dependent on the constituents of the cell surface. Since the SLP is the outermost structure in many bacteria and has been suggested to play an important role in the attachment of several bacterial species to different surfaces (Kotiranta et al. 1998; Schneitz et al. 1993; Sakakibara et al. 2007), the role of SLP in biofilm formation has been investigated for different biofilm-forming bacteria such as Clostridium difficile, Bacillus cereus and Tannerella forsythia.

The SLP of $C$. difficile consists of two protein subunits derived from the same precursor, SlpA, which undergoes a proteolytic cleavage mediated by the Cwp 84 protease. No SlpA mutant has been obtained to date, but a mutant in cwp84 was shown to be defective in S-layer synthesis (Kirby et al. 2009). Dapa et al. (2013) found that the cwp 84 mutant strain had no defect in planktonic growth but had an important decrease in biofilm accumulation as compared to the R20291 parent strain, and that the biofilm defect for the cwp 84 strain was fully complemented by restoring the wild type gene on the chromosome, suggesting that a mature S-layer is essential for $C$. difficile biofilm formation in this strain. In turn, Pantaléon et al. (2015) found that the biofilm formed by the cwp 84 mutant strain was 72 -fold increased over that of the $6304 \mathrm{erm}$ parent or complemented cwp 84 mutant, and suggested that the accumulation of uncleaved SlpA (occurring in the biofilm matrix of the cwp 84 mutant) may promote biofilm formation and enhance the bacterial interactions. Since Cwp84 is involved in proteolytic maturation of several other surface proteins, the effect of cwp84 mutation in biofilm formation could go beyond the defect in SLP formation. In Bacillus cereus the presence of SLP was negatively correlated with biofilm formation (Kotiranta et al. 1998; Auger et al. 2009). 
Tannerella forsythia is an oral biofilm forming bacteria which possesses an S-layer composed of two glycoproteins, TfsA and TfsB (Lee et al. 2006). In these bacteria, the expression of SLP in cells growing in biofilm is significantly higher than in planktonic cells, while the wecC gen, involved in the glycosylation of several surface proteins, is downregulated in biofilm cells (Pham et al. 2010). Mutants lacking a functional wecC gen showed increased surface hydrophobicity and increased biofilm formation as compared to the parental strain (Honma et al. 2007). These mutants lacked a normal S-layer, and contained proteins TfsA and TfsB with a lower molecular mass, due to a reduced glycosylation degree (Posch et al. 2011). Posch et al. (2011) found that the truncated SLP glycan lacks an acidic branch, and postulated that these acidic residues could contribute to charge repulsive forces which impair biofilm formation under physiological conditions of the oral cavity. In the same sense, in studies conducted in mutants deficient in the type IX secretion system, that also lacked a S-layer and expressed less-glycosylated versions of proteins TfsA and TfsB, biofilm formation tendency was higher than in wild type cells (Narita et al. 2014). These findings suggest that if not the S-layer per se, at least its glycosylation degree and type of glycans strongly influence the biofilm life-style of oral pathogen $T$. forsythia.

\section{Interaction with the immune system}

The first investigations about the role of SLP in the immune response against bacteria date back to a few years ago. They include the interaction with SLP from both pathogenic and not pathogenic microorganisms (Fig. 1d). For pathogenic bacteria, SLPs constitute useful tools for evading the host immune system mechanisms. In Campylobacter fetus, a pathogen that causes disseminated bloodstream disease, SLP confers resistance to complement-mediated killing by preventing the binding of complement factor $\mathrm{C} 3 \mathrm{~b}$ to the surface and has also evolved for avoiding antibody-mediated killing by high-frequency antigenic variation of SLPs (Thompson 2002). Although less extensively studied, assays performed with an isogenic mutant lacking a SLP, have shown that the SLP of periodontal pathogen $C$. rectus appears also to induce a downregulation of proinflammatory cytokines such as IL-8, IL-6 and TNF- $\alpha$ (Wang et al. 2000). Similar results were reported by Sekot et al. (2011) who studied the immune response of human macrophages and gingival fibroblasts upon stimulation with wild-type Tannerella forsythia and a SLP-deficient mutant. More recently, Settem et al. (2013) observed that the terminal motif of the $T$. forsythia S-layer glycan core acts to modulate dendritic cells effector functions to suppress Th17 responses, demonstrating that glycosylation of this pathogen contributes to its persistence in the host. As the major surface antigens of $C$. difficile, the SlpA proteins lead to the release of proinflammatory cytokines from human monocytes and to the maturation of human monocyte-derived dendritic cells (Ausiello et al. 2006), through the recognition of Toll-like receptor 4 (TLR4), subsequently inducing $\mathrm{T}$ helper cell responses that are known to be involved in bacterial clearance (Ryan et al. 2011) (Fig. 1d).

Besides pathogens, the involvement of SLP in the microbe-induced immune response has been also studied for some potentially probiotic bacteria. In 2008, Konstantinov et al. (2008) demonstrated that SlpA of L. acidophilus NCFM interacts with DC-SIGN on dendritic cell (DC) surface, since a knockout mutant lacking the SlpA was significantly reduced in binding to DC-SIGN. In this SLP B-dominant strain, the nature of the interaction with DCs changed dramatically, leading to the secretion of higher concentrations of proinflammatory cytokines (i.e., IL-12p70, TNF $\alpha$ and IL-1 $\beta$ ) (Fig. 1d). More recently, Taverniti et al. (2013) showed that purified SlpA of $L$. helveticus MIMLh5 exerts anti-inflammatory effects by reducing the activation of $\mathrm{NF}-\kappa \mathrm{B}$ on the intestinal epithelial Caco- 2 cells, meanwhile acts as stimulator of the innate immune system by triggering the expression of pro-inflammatory factors in the human macrophage cell line U937 via recognition through Toll-like receptor 2. A similar response was observed following stimulation of macrophages isolated from mouse bone marrow or peritoneal cavity.

Some immunomodulatory properties were also assessed for SLP of Propionibacterium freudenreichii, a beneficial bacterium used in the food industry as a vitamin producer, biopreservative, cheese ripening starter and probiotic. A surface protein extract from $P$. freudenreichii ITG P20 drastically reduced the induction of cytokines IL-12, IFN- $\gamma$ and TNF- $\alpha$ when applied in conjunction with the proinflammatory Lactococcus lactis MG1363 (Le Maréchal et al. 2015). In our group the effect of SLP from L. kefiri on activation of antigen presenting cells (macrophages and dendritic cells) is being assessed in presence and absence of TLR-agonist.

\section{Role of SLP as mechanical barriers in harmful environments}

\section{Resistance to gastrointestinal conditions}

The gastrointestinal tract is an environment full of stressful conditions, including low $\mathrm{pH}$, proteolytic enzymes, digestive juices, etc. Therefore, different authors investigated the role of SLP in protecting microorganisms in these harmful conditions (Fig. 1e). 
The viability of $L$. acidophilus M92 without SLP decreases in simulated gastric juice at low $\mathrm{pH}$ and simulated pancreatic juice with bile salts (Frece et al. 2005). SLP of L. acidophilus M92 are resistant to pepsin and pancreatin. However, the treatment with proteinase $\mathrm{K}$ leads to a significant proteolysis of SLP. These results demonstrate the protective role of SLP when microorganisms are exposed to gastrointestinal conditions (Fig. 1e).

Based on previus works demonstrating that L. acidophilus ATCC4356 wearing SLP are stable in harsh gastrointestinal conditions, Eslami et al. (2013) investigated and demonstrated the in vitro stability of isolated SLP expossed to simulated gastric fluid with and without pepsin.

Meng et al. (2014) reported that after removing SLPs from three strains of L. acidophilus and L. helveticus the survival in simulated gastric and intestinal juices was reduced by 2-3 $\log$ as compared with survival of the intact cells.

The expression of SLP in different conditions of fermentation medium was studied for $L$. acidophilus NCC2628 by Schar-Zammaretti et al. (2005). They observed that in the absence of peptones, the overall protein content of cell wall is significantly lower than in complete medium, whereas the expression of SLP is strongly enhanced. This suggests that SLP could be preferentially expressed in conditions that are not optimal for bacterial growth. These results are in agreement with those reported by Khaleghi and coworkers who demonstrated that SLP and $\operatorname{slpA}$ gene expression were altered by different stress conditions in the probiotic strain L. acidophilus ATCC 4356. First, the amount of SLP increased in presence of $0.01-0.1 \%$ bile, and the SlpA encoding gene expression showed a similar behavior (Khaleghi et al. 2010).

\section{Resistance to other adverse environmental conditions}

The strong resistance of SLP to extreme environmental conditions (i.e., high temperatures, low $\mathrm{pH}$, high ionic strength) suggests a potential role of these proteins in protecting and stabilizing cells (Engelhardt and Peters 1998; Claus et al. 2002; Engelhardt 2007). This is especially true in Gram-negative extremophile archaea, in which SLPs are directly anchored into the cytoplasmic membrane.

As outermost bacterial structures, S-layers are directly exposed to these extreme environmental conditions, thus provide useful information about the molecular mechanisms involved in protein stabilization at high temperatures (Fig. 1e). Thermal stabilization of SLP has been mainly ascribed to posttranslational modifications (i.e., glycosilation), covalent cross-linking or salt-bridging (Engelhardt and Peters 1998). Claus et al. (2002) addressed this issue in a comparative review on SLP of mesophilic and extremely thermophilic archaea.

In Deinococcus radiodurans $\mathrm{R} 1$, two proteins are involved in the maintenance and integrity of SLP: the hexagonally packed intermediate (Hpi) protein, and SlpA (DR2577). Deletion of the hpi gene has little effect on the structure of the cell envelope or on shear- or solvent-induced stress responses. On the contrary, deletion of the $\operatorname{slp} A$ gene causes substantial alterations in cell envelope structure, and a significant defect in the resistance to solvent and shear stresses compared to the wild-type. Ultrastructural analysis of $\operatorname{slp} A$ mutant cells indicated loss of much of the outer Hpi protein carbohydrate coat and the membrane-like backing layer (Rothfuss et al. 2006).

Other authors assessed the role of SLP of D. acidovorans $\mathrm{Cs} 1-4$ on the phenanthrene uptake. Their role in phenanthrene biodegradation appears to be the enhancement of the cellular retention of phenanthrene catabolism metabolites (Shetty and Hickey 2014).

Butler et al. (2013) investigated the symbiotic lactic acid bacteria microbiota of the honeybee Apis mellifera, composed of Lactobacillus and Bifidobacterium. This microbiota is symbiotic either with their host or with the visited flowers. This defends the microbiota niche against other bacteria and yeasts introduced by nectar foraging and food intake. Because of the selective pressure from environmental changes in their niche, lactic acid bacteria evolved stress response systems and defenses that enable them to grow and survive in harsh conditions. The honey crop, with its constant nectar flow, high osmotic pressure, and presence of microorganisms introduced by foraging is the ideal environment for these systems to be activated. In these conditions, lactic acid bacteria can produce great amounts of cell surface and extra-cellular proteins (i.e., bacteriocins, molecular chaperones, enzymes, lipoproteins, and SLP), which are essential for niche protection. In these bacteria, the protective role of SLP has been hypothetically ascribed to their capacity to inhibit the muramidases they secrete, that destroy the foreign bacteria cell walls.

SLPs have also been reported to be responsible for the high resistance of Deinococcus radiodurans to high concentrations of $\mathrm{NaCl}$ (Fig. 1e). When exposed to $0.3 \mathrm{M}$ $\mathrm{NaCl}$, D. radiodurans activates genes associated with osmoprotectant accumulation: the pstSCAB operon, which encodes a high affinity phosphate transporter, and DRA0135 and DR1438, which are components of transporters of glycine betaine and trehalose. Survival analysis of mutant strains lacking DR0392 (membrane-binding protein) and DR1115 (SLP), whose expressions are activated by $\mathrm{NaCl}$, show a reduction in $\mathrm{NaCl}$ tolerance (Im et al. 2013). 
In Gram-negative bacteria such as Aquaspirillum serpens and Caulobacter crescentus the SLP may play a protective role against predation by the parasitic bacterium Bdellovibrio bacterovirus (Fig. 1e) (Koval and Hynes 1991).

A key role in removing toxic metals from contaminated soils and sediments has also been ascribed to SLPs. Soils, sediments and water present in the mining areas contain high concentration of metals and radionuclides, and act as reservoirs of unusual bacteria well adapted to these harmful conditions (Fig. 1e). These bacteria possess different mechanisms for interaction and biotransformation metals and radionucleides, including biosorption and bioacumulation (Hennig et al. 2001; Merroun and Selenska-Pobell 2001; Merroun et al. 2003).

One of the most extensively studied microorganisms for the capacity to bind both precious and toxic metals is Lysinibacillus sphaericus strain JG-A12, a strain isolated from a uranium mining waste pile near Johanngeorgenstadt [Saxony, Germany (Raff et al. 2002; Pollmann et al. 2006)]. For this reason, it is a strain that naturally evolved under chronic exposure to uranium, and thus, has an intrinsic tolerance to the radioactive compound (SelenskaPobell et al. 1999; Pollmann et al. 2005) and bind uranyl ions with high specificity (Gupta et al. 2002). This background led to the development of SLP-based biosensors responding specifically to these ions (Conroy et al. 2010).

Besides uranyl ions, other metals, including $\mathrm{Al}, \mathrm{Au}, \mathrm{Ba}$, $\mathrm{Cd}, \mathrm{Co}, \mathrm{Cr}, \mathrm{Cs}, \mathrm{Cu}, \mathrm{Fe}, \mathrm{Ga}, \mathrm{Mn}, \mathrm{Ni}, \mathrm{Rb}, \mathrm{Si}, \mathrm{Sn}, \mathrm{Sr}, \mathrm{Ti}, \mathrm{U}$, and $\mathrm{Zn}$, can be adsorbed on the surface of Lys. sphaericus JG-A12 (Merroun et al. 2005; Jankowski et al. 2010). Also in this case, SLPs have been indicated as the structures involved in biosorption, probably providing a protective function by preventing the cellular uptake of heavy metals and radionuclides (Fahmy et al. 2006).

Other species of microorganisms bearing SLP have been isolated from these uranium mines in Germany, and include Metallosphaera prunae, sp. nov., an archea growing between 55 and $80{ }^{\circ} \mathrm{C}$, bearing SLP (Fuchs et al. 1995), and Lys. sphaericus JG-B53. Essential trace elements are able to cross the filter layer and reach the interior of this latter strain, which possesses outstanding recrystallization and metal-binding properties (Lederer et al. 2013). The genome of Lys. sphaericus JG-B53 encodes at least eight putative SLP genes with distinct differences. The presence of multiple SLP gene copies may enable the bacterial strains to quickly adapt to changing environments. This multiplicity of SLP in Lys. sphaericus JG-B53 provides an indication of intensive cell stressors, enabling their survival in such harsh environments.

Velazquez and Dussan (2009) also ascribed the capacity of different colombian Lys. sphaericus native strains to adsorb arsenic, mercury, iron and chromium, to their SLP.
Aravindh et al. (2015) isolated six different bacterial strains from thorium mine ore samples collected from Indian Rare Earth Limited [Manavalakurichi (IREL), India]. The most resistant organism was identified as Bacillus spp. and demonstrated to be resistant towards variation of $\mathrm{pH}$, and increasing concentrations of uranium and gamma radiation. In turn, Bacillus sp. HKG 112 isolated from the saline soils of Jangpura in India also resists high level of gamma radiation (up to $12.5 \mathrm{kGy}$ ) (Gupta et al. 2011). SLPs were indicated as potential responsible for the radiation resistance in both cases. The different responses of some genes under radiation for the expression of radiation-dependent proteins could contribute to a physiological advantage and would be a significant initial step towards a full system understanding of the radiation stress protection mechanisms of bacteria in different environments.

Other authors showed that spores of Bacillus thuringiensis are proficient for copper biosorption. This capacity was ascribed to the retention of SLP by spores, as removal of SLP leads to significant reduction of copper biosorption (Allievi et al. 2011).

The cyanobacterium Synechococcus spp. GL24, isolated from a meromictic Fayetteville Green Lake (NY, USA) with high levels of calcium and sulphate ions, bear hexagonal SLP that can act as templates for sulphate and carbonate mineral formation on the bacterial surface (Schultzelam and Beveridge 1994a, b).

Finally, although the capacity of lactic acid bacteria to interact with different metals have been addressed, the role of SLP in metal biosorption has only been reported for $L$. kefiri. Gerbino et al. (2015) addressed the capacity of $L$. kefiri strains to sequester $\mathrm{Pb}^{2+}$ before and after removing SLPs with proteinase K. They found that bacteria without SLP increased their sequestrant capacity. The removal of SLP had no significant effect on bacterial viability in control conditions, but microorganisms without SLP were more prone to the detrimental effect of $\mathrm{Pb}^{2+}$, thus suggesting that the S-layer acts as a protective rather than as a sequestrant layer in this strain.

\section{Conclusions}

Since the first reports in the middle seventies great advances have been developed in regard to structural aspects of SLPs. Indeed, the functional properties of S-layers in bacteria are doubtless related with their structure. For this reason, research on SLPs represents nowadays a multidisciplinary field in which very different aspects can be addressed. Up to our knowledge, most of the reports dealing with the role of S-layers on bacteria refer to functional aspects assessed in a very descriptive way. In 
fact, the functions ascribed to S-layers in bacteria are determined by simply removing S-layers and proving that the property under study is lost. In turn, reports dealing with the structure and biophysical properties of S-layers are mostly carried out on isolated S-layers. Biophysical methods together with computer modelling-based programs are increasingly utilized to perform structural studies on pure S-layers. However, an integration between functional and structural aspects of S-layers is still lacking. In this regard, the relation between structure and function of both the protein sequence and the sugars present in several S-layers is absolutely necessary to understand many of the S-layer properties reported hereto.

The integration of these two approaches will enable researchers to obtain high-resolved structural information, thus contributing for the understanding of the real functions of SLPs when wearing the bacterial surface.

Acknowledgments This work was supported by the Argentinean Agency for the Scientific and Technological Promotion (ANPCyT) (Projects PICT/2011/0226, PICT/2013/1258 and PICT/2014/912), the Argentinean National Research Council (CONICET) (PIP2012-2014114201101-00024). E.G., P.M., M.A.S. and A.G.-Z. are members of the research career CONICET. P.C. is postdoctoral fellow of CONICET.

\section{Compliance with ethical standards}

Conflict of interest The authors declare that they have no conflict of interest.

\section{References}

Ahn JS, Chandramohan L, Liou LE, Bayles KW (2006) Characterization of CidR-mediated regulation in Bacillus anthracis reveals a previously undetected role of S-layer proteins as murein hydrolases. Mol Microbiol 62:1158-1169

Allievi MC, Sabbione F, Prado-Acosta M, Palomino MM, Ruzal SM, Sanchez-Rivas C (2011) Metal biosorption by surface-layer proteins from Bacillus species. J Microbiol Biotechnol 21:147-153

Aravindh S, Selvakumar R, Ravichandran J, Kamachi Mudali U, Anandbabu C, Raj B (2015) Extremophilic Bacillus cereus MVK04 Isolated from thorium ore sample possesses selfassembled surface layer protein on cell wall to resist extreme environments. Geomicrobiol J 32:445-452

Auger S, Ramarao N, Faille C, Fouet A, Aymerich S, Gohar M (2009) Biofilm formation and cell surface properties among pathogenic and nonpathogenic strains of the Bacillus cereus group. Appl Environ Microbiol 75:6616-6618

Ausiello CM, Cerquetti M, Fedele G, Spensieri F, Palazzo R, Nasso M, Frezza S, Mastrantonio P (2006) Surface layer proteins from Clostridium difficile induce inflammatory and regulatory cytokines in human monocytes and dendritic cells. Microbes Infect 8:2640-2646

Åvall-Jääskeläinen S, Lindholm A, Palva A (2003) Surface display of the receptor-binding region of the Lactobacillus brevis S-layer protein in Lactococcus lactis provides nonadhesive lactococci with the ability to adhere to intestinal epithelial cells. Appl Environ Microbiol 69:2230-2236
Beganović J, Frece J, Kos B, Leboš Pavunc A, Habjanič K, Sušković J (2011) Functionality of the S-layer protein from the probiotic strain Lactobacillus helveticus M92. Antonie Van Leeuwenhoek 100:43-53

Buck B, Altermann E, Svingerud T, Klaenhammer TR (2005) Functional analysis of putative adhesion factors in Lactobacillus acidophilus NCFM. Appl Environ Microbiol 71:8344-8351

Butler E, Alsterfjord M, Olofsson TC, Karlsson C, Malmström J, Vásquez A (2013) Proteins of novel lactic acid bacteria from Apis mellifera mellifera: an insight into the production of known extra-cellular proteins during microbial stress. BMC Microbiol $13: 235-246$

Calabi E, Ward S, Wren B, Paxton T, Panico M, Morris H, Dell A, Dougan G, Fairweather N (2001) Molecular characterization of the surface layer proteins from Clostridium difficile. Mol Microbiol 40:1187-1199

Calabi E, Calabi F, Phillips AD, Fairweather N (2002) Binding of Clostridium difficile surface layer proteins to gastrointestinal tissues. Infect Immun 70:5770-5778

Callegari ML, Riboli B, Sanders JW, Cocconcelli PS, Kok J, Venema G, Morelli L (1998) The S-layer gene of Lactobacillus helveticus CNRZ 892: cloning, sequence and heterologous expression. Microbiology 144(Pt 3):719-726

Carasi P, Ambrosis NM, De Antoni GL, Bressollier P, Urdaci MC, Serradell MDLA (2014) Adhesion properties of potentially probiotic Lactobacillus kefiri to gastrointestinal mucus. J Dairy Res 81:16-23

Chen X, Xu J, Shuai J, Chen J, Zhang Z, Fang W (2007) The S-layer proteins of Lactobacillus crispatus strain ZJ001 is responsible for competitive exclusion against Escherichia coli $\mathrm{O} 157: \mathrm{H} 7$ and Salmonella Typhimurium. Int J Food Microbiol 115:307-331

Claus H, Akca E, Debaerdemaeker T, Evrard C, Declercq JP, Konig H (2002) Primary structure of selected archaeal mesophilic and extremely thermophilic outer surface layer proteins. Syst Appl Microbiol 25:3-12

Conroy DJR, Millner PA, Stewart DI, Pollmann K (2010) Biosensing for the environment and defence: aqueous uranyl detection using bacterial surface layer proteins. Sensors 10:4739-4755

Dapa T, Leuzzi R, Ng YK, Baban ST, Adamo R, Kuehne SA, Scarselli M, Minton NP, Serruto D, Unnikrishnan M (2013) Multiple factors modulate biofilm formation by the anaerobic pathogen Clostridium difficile. J Bacteriol 195:545-555

de Leeuw E, Li X, Lu W (2006) Binding characteristics of the Lactobacillus brevis ATCC 8287 surface layer to extracellular matrix proteins. FEMS Microbiol Lett 260:210-215

Engelhardt H (2007) Mechanism of osmoprotection by archaeal S-layers: a theoretical study. J Struct Biol 160:190-199

Engelhardt H, Peters J (1998) Structural research on surface layers: a focus on stability, surface layer homology domains, and surface layer-cell wall interactions. J Struct Biol 124:276-302

Eslami N, Kermanshahi RK, Erfan M (2013) Studying the stability of S-layer protein of Lactobacillus acidophilus ATCC 4356 in simulated gastrointestinal fluids using SDS-PAGE and circular dichroism. Iran J Pharm Res 12:47-56

Fahmy K, Merroun M, Pollmann K, Raff J, Savchuk O, Hennig C, Selenska-Pobell S (2006) Secondary structure and Pd(II) coordination in S-layer proteins from Bacillus sphaericus studied by infrared and X-ray absorption spectroscopy. Biophys J 91:996-1007

Flemming HC, Wingender J (2010) The biofilm matrix. Nat Rev Microbiol 8:623-633

Frece J, Kos B, Svetec IK, Zgaga Z, Mrša V, Šušković J (2005) Importance of $S$ layer proteins in probiotic activity of Lactobacillus acidophilus M92. J Appl Microbiol 98:285-292

Fuchs T, Huber H, Teiner K, Burggraf S, Stetter K (1995) Metallosphaera prunae, sp. nov., a novel metal-mobilizing, 
Thermoacidophilic archaeum, isolated from a uranium mine in Germany. Syst Appl Microbiol 18:560-566

Garrote G, Delfederico L, Bibiloni R, Abraham AG, Pérez P, Semorile L, De Antoni G (2004) Heterofermentative lactobacilli isolated from kefir grains: evidence for the presence of S-layer proteins. J Dairy Res 71:222-230

Gerbino E, Carasi P, Araujo-Andrade C, Tymczyszyn E, GomezZavaglia A (2015) Role of S-layer proteins in the biosorption capacity of lead by Lactobacillus kefir. World J Microbiol Biotechnol 31:583-592

Gilmour R, Messner P, Guffanti AA, Kent R, Scheberl A, Kendrick N, Krulwich TA (2000) Two-dimensional gel electrophoresis analyses of $\mathrm{pH}$-dependent protein expression in facultatively alkaliphilic Bacillus pseudofirmus OF4 lead to characterization of an S-layer protein with a role in alkaliphily. J Bacteriol 182:5969-5981

Golowczyc MA, Mobili P, Garrote GL, Serradell MA, Abraham AG, De Antoni GL (2009) Interaction between Lactobacillus kefir and Saccharomyces lipolytica isolated from kefir grains: evidence for lectin-like activity of bacterial surface proteins. J Dairy Res 76:1-6

Greene JD, Klaenhammer TR (1994) Factors involved in adherence of lactobacilli to human Caco-2 cells. Appl Environ Microbiol 60:4487-4494

Gupta RK, Dobritsa SV, Stiles CA, Essington ME, Liu ZY, Chen CH, Serpersu EH, Mullin BC (2002) Metallohistins: a new class of plant metal-binding proteins. J Protein Chem 21:529-536

Gupta AK, Pathak R, Singh B, Gautam H, Kumar R, Kumar R, Arora R, Gautam HK (2011) Proteomic analysis of global changes in protein expression during exposure of gamma radiation in Bacillus sp. HKG 112 isolated from saline soil. J Microbiol Biotechnol 21:574-581

Hennig C, Panak PJ, Reich T, Roßberg A, Raff J, Selenska-Pobell S, Matz W, Bucher JJ, Bernhard G, Nitsche H (2001) EXAFS investigation of uranium(VI) complexes formed at Bacillus cereus and Bacillus sphaericus surfaces. Radiochim Acta 89:625-631

Honma K, Inagaki S, Okuda K, Kuramitsu HK, Sharma A (2007) Role of a Tannerella forsythia exopolysaccharide synthesis operon in biofilm development. Microb Pathog 42:156-166

Horie M, Ishiyama A, Fujihira-Ueki Y, Sillanpää J, Korhonen TK, Toba T (2002) Inhibition of the adherence of Escherichia coli strains to basement membrane by Lactobacillus crispatus expressing an S-layer. J Appl Microbiol 92:396-403

Hynönen U, Palva A (2013) Lactobacillus surface layer proteins: structure, function and applications. Appl Microbiol Biotechnol 97:5225-5543

Hynönen U, Westerlund-Wikström B, Palva A, Korhonen TK (2002) Identification by flagellum display of an epithelial cell- and fibronectin-binding function in the SlpA surface protein of Lactobacillus brevis. J Bacteriol 184:3360-3367

Im S, Joe M, Kim D, Park DH, Lim S (2013) Transcriptome analysis of salt-stressed Deinococcus radiodurans and characterization of salt-sensitive mutants. Res Microbiol 164:923-932

Jakava-Viljanen M, Palva A (2007) Isolation of surface (S) layer protein carrying Lactobacillus species from porcine intestine and faeces and characterization of their adhesion properties to different host tissues. Vet Microbiol 124:264-273

Jankowski U, Merroun ML, Selenska-Pobell S, Fahmy K (2010) S-Layer protein from Lysinibacillus sphaericus JG-A12 as matrix for AuIII sorption and Au-nanoparticle formation. Spectroscopy 24:177-181

Khaleghi M, Kermanshahi RK, Yaghoobi MM, Zarkesh-Esfahani SH, Baghizadeh A (2010) Assessment of bile salt effects on S-layer production, slp gene expression, and some physicochemical properties of Lactobacillus acidophilus ATCC 4356. J Microbiol Biotechnol 20:749-756
Kirby JM, Ahern H, Roberts AK, Kumar V, Freeman Z, Acharya KR, Shone CC (2009) Cwp84, a surface-associated cysteine protease, plays a role in the maturation of the surface layer of Clostridium difficile. J Biol Chem 284:34666-34673

Konstantinov SR, Smidt H, de Vos WM, Bruijns SC, Singh SK, Valence F, Molle D, Lortal S, Altermann E, Klaenhammer TR, van Kooyk Y (2008) S-layer protein A of Lactobacillus acidophilus NCFM regulates immature dendritic cell and T cell functions. Proc Natl Acad Sci USA 105:19474-19479

Kos B, Šušković J, Vuković S, Šimpraga M, Frece J, Matošić S (2003) Adhesion and aggregation ability of probiotic strain Lactobacillus acidophilus M92. J Appl Microbiol 94:981-987

Kotiranta A, Haapasalo M, Kari K, Kerosuo E, Olsen I, Sorsa T, Meurman JH, Lounatmaa K (1998) Surface structure, hydrophobicity, phagocytosis, and adherence to matrix proteins of Bacillus cereus cells with and without the crystalline surface protein layer. Infect Immun 66:4895-4902

Kotiranta AK, Ito H, Haapasalo MP, Lounatmaa K (1999) Radiation sensitivity of Bacillus cereus with and without a crystalline surface protein layer. FEMS Microbiol Lett 179:275-280

Koval SF, Hynes SH (1991) Effect of paracrystalline protein surface layers on predation by Bdellovibrio bacteriovorus. J Bacteriol 173:2244-2249

Le Maréchal C, Peton V, Plé C, Vroland C, Jardin J, Briard-Bion V, Durant G, Chuat V, Loux V, Foligné B, Deutsch SM, Falentin H, Jan G (2015) Surface proteins of Propionibacterium freudenreichii are involved in its anti-inflammatory properties. J Proteomics 113:447-461

Lederer FL, Weinert U, Gunther TJ, Raff J, Weiß S, Pollmann K (2013) Identification of multiple putative S-layer genes partly expressed by Lysinibacillus sphaericus JG-B53. Microbiology 159:1097-1108

Lee SW, Sabet M, Um HS, Yang J, Kim HC, Zhu W (2006) Identification and characterization of the genes encoding a unique surface (S-) layer of Tannerella forsythia. Gene 371:102-111

Li Q, Liu X, Zhou J, Wang Y (2015) Aggregation and adhesion abilities of 18 lactic acid bacteria strains isolated from traditional fermented food. Int J Agric Policy Res 3:84-92

Lortal S, van Heijenoort J, Gruber K, Sleytr UB (1992) S-layer of Lactobacillus helveticus ATCC 12046: isolation, chemical characterization and reformation after extraction with lithium chloride. J Gen Microbiol 138:611-618

Marsh PD, Moter A, Devine DA (2011) Dental plaque biofilms: communities, conflict and control. Periodontol 2000 55:16-35

Meng J, Zhu X, Gao SM, Zhang QX, Sun S, Lu R (2014) Characterization of surface layer proteins and its role in probiotic properties of three Lactobacillus strains. Int J Biol Macromol 65:110-114

Merroun ML, Selenska-Pobell S (2001) Interactions of three ecotypes of Acidithiobacillus ferrooxidans with U(VI). Biometals 14:171-179

Merroun ML, Geipel G, Nicolai R, Heise K-H, Selenska-Pobell S (2003) Complexation of uranium (VI) by three eco-types of Acidithiobacillus ferrooxidans studied using time-resolved laserinduced fluorescence spectroscopy and infrared spectroscopy. Biometals 16:331-339

Merroun ML, Raff J, Rossberg A, Hennig C, Reich T, SelenskaPobell S (2005) Complexation of uranium by cells and S-layer sheets of Bacillus sphaericus JG-A12. Appl Environ Microbiol 71:5532-5543

Muñoz-Provencio D, Llopis M, Antolín M, de Torres I, Guarner F, Pérez-Martínez G, Monedero V (2009) Adhesion properties of Lactobacillus casei strains to resected intestinal fragments and components of the extracellular matrix. Arch Microbiol 191:153-161 
Narita Y, Sato K, Yukitake H, Shoji M, Nakane D, Nagano K, Yoshimura F, Naito M, Nakayama K (2014) Lack of a surface layer in Tannerella forsythia mutants deficient in the type IX secretion system. Microbiology 160:2295-2303

Pantaléon V, Soavelomandroso AP, Bouttier S, Briandet R, Roxas B, Chu M, Collignon A, Janoir C, Vedantam G, Candela T (2015) The Clostridium difficile protease cwp84 modulates both biofilm formation and cell-surface properties. PLoS One 10:e0124971

Pham TK, Roy S, Noirel J, Douglas I, Wright PC, Stafford GP (2010) A quantitative proteomic analysis of biofilm adaptation by the periodontal pathogen Tannerella forsythia. Proteomics 10:3130-3141

Pollmann K, Raff J, Schnorpfeil M, Radeva G, Selenska-Pobell S (2005) Novel surface layer protein genes in Bacillus sphaericus associated with unusual insertion elements. Microbiology 151:2961-2973

Pollmann K, Raff J, Merroun M, Fahmy K, Selenska-Pobell S (2006) Metal binding by bacteria from uranium mining waste piles and its technological applications. Biotechnol Adv 24:58-68

Poppinga L, Janesch B, Fünfhaus A, Sekot G, Garcia-Gonzalez E, Hertlein G, Hedtke K, Schäffer C, Genersch E (2012) Identification and functional analysis of the S-Layer protein SplA of Paenibacillus larvae, the causative agent of american foulbrood of honey bees. PLoS Pathog 8:e1002716

Posch G, Pabst M, Brecker L, Altmann F, Messner P, Schäffer C (2011) Characterization and scope of S-layer protein O-glycosylation in Tannerella forsythia. J Biol Chem 286:38714-38724

Prado Acosta M, Palomino M, Allievi MC, Sanchez Rivas C, Ruzal SM (2008) Murein hydrolase activity in the surface layer of Lactobacillus acidophilus ATCC 4356. Appl Environ Microbiol 74:7824-7827

Raff J, Soltmann U, Matys S, Schnorpfeil M, Böttcher H, Pompe W, Selenska-Pobell S (2002) Bacterial-based bioremediation of uranium mining waste waters by using sol-gel ceramics. In: Merkel BJ, Planer-Friedrich B, Wolkersdorfer C (eds) Uranium in the aquatic environment. Proceedings of the international conference uranium mining and hydrogeology III and the international mine water association symposium, Freiberg, Springer, Berlin, Heidelberg, New York, pp 615-622

Rothfuss H, Lara JC, Schmid AK, Lidstrom ME (2006) Involvement of the S-layer proteins Hpi and SlpA in the maintenance of cell envelope integrity in Deinococcus radiodurans R1. Microbiology 152:2779-2787

Ryan A, Lynch M, Smith SM, Amu S, Nel HJ, McCoy CE, Dowling JK, Draper E, O'Reilly V, McCarthy C, O'Brien J, Eidhin DN, O'Connell MJ, Keogh B, Morton CO, Rogers TR, Fallon PG, O'Neill LA, Kelleher D, Loscher CE (2011) A role for TLR4 in Clostridium difficile infection and the recognition of surface layer proteins. PLoS Pathog 7:e1002076

Sakakibara J, Nagano K, Murakami Y, Higuchi N, Nakamura H, Shimozato K, Yoshimura F (2007) Loss of adherence ability to human gingival epithelial cells in S-layer protein-deficient mutants of Tannerella forsythensis. Microbiology 153: 866-876

Sánchez B, Arias S, Chaignepain S, Denayrolles M, Schmitter JM, Bressollier P, Urdaci MC (2009) Identification of surface proteins involved in the adhesion of a probiotic Bacillus cereus strain to mucin and fibronectin. Microbiology $155(\mathrm{Pt}$ 5): $1708-1716$

Sara M, Sleytr UB (2000) S-layer proteins. J Bacteriol 182:859-868 Schar-Zammaretti P, Dillmann M-L, D'Amico N, Affolter M, Ubbink $\mathrm{J}$ (2005) Influence of fermentation medium composition on physicochemical surface properties of Lactobacillus acidophilus. Appl Environ Microbiol 71:8165-8173
Schneitz C, Nuotio L, Lounatma K (1993) Adhesion of Lactobacillus acidophilus to avian intestinal epithelial cells mediated by the crystalline bacterial cell surface layer (S-layer). J Appl Bacteriol 74:290-294

Schultzelam S, Beveridge TJ (1994a) Nucleation of celestite and strontianite on a cyanobacterial S-layer. Appl Environ Microbiol 60:447-453

Schultzelam S, Beveridge TJ (1994b) Physicochemical characteristics of the mineral-forming Slayer from the Cyanobacterium synechococcus strain G124. Can J Microbiol 40:216-223

Sekot G, Posch G, Messner P, Matejka M, Rausch-Fan X, Andrukhov O, Schäffer C (2011) Potential of the Tannerella forsythia S-layer to delay the immune response. J Dent Res 90:109-114

Selenska-Pobell S, Panak P, Miteva V, Boudakov I, Bernhard G, Nitsche H (1999) Selective accumulation of heavy metals by three indigenous Bacillus strains, B. cereus, B. megaterium and $B$. sphaericus, from drain waters of a uranium waste pile. FEMS Microbiol Ecol 29:59-67

Settem RP, Honma K, Nakajima T, Phansopa C, Roy S, Stafford GP, Sharma A (2013) A bacterial glycan core linked to surface (S)layer proteins modulates host immunity through Th17 suppression. Mucosal Immunol 6:415-426

Shetty A, Hickey WJ (2014) Effects of outer membrane vesicle formation. Surface-layer production and nanopod development on the metabolism of phenanthrene by Delftia acidovorans Cs14. PlosOne 9:e92143

Shimotahira N, Oogai Y, Kawada-Matsuo M, Yamada S, Fukutsuji K, Nagano K, Yoshimura F, Noguchi K, Komatsuzawa H (2013) The surface layer of Tannerella forsythia contributes to serum resistance and oral bacterial coaggregation. Infect Immun 81:1198-1206

Sillanpaa J, Martinez B, Antikainen J, Toba T, Kalkkinen N, Tankka S, Lounatmaa K, Jaakko Keränen J, Höök M, WesterlundWikström B, Pouwels PH, Korhonen TK (2000) Characterization of the collagen-binding S-layer protein CbsA of Lactobacillus crispatus. J Bacteriol 182:6440-6450

Sleytr UB, Beveridge TJ (1999) Bacterial S-layers. Trends Microbiol 7:253-260

Sleytr UB, Sára M, Pum D, Schuster B (2001) Characterization and use of crystalline bacterial cell surface layers. Prog Surf Sci 68:231-278

Sun Z, Kong J, Hu S, Kong W, Lu W, Liu W (2013) Characterization of a S-layer protein from Lactobacillus crispatus K313 and the domains responsible for binding to cell wall and adherence to collagen. Appl Microbiol Biotechnol 97:1941-1952

Taverniti V, Stuknyte M, Minuzzo M, Arioli S, De Noni I, Scabiosi C, Cordova ZM, Junttila I, Hämäläinen S, Turpeinen H, Mora D, Karp M, Pesu M, Guglielmetti S (2013) S-layer protein mediates the stimulatory effect of Lactobacillus helveticus MIMLh5 on innate immunity. Appl Environ Microbiol 79:1221-1231

Thompson SA (2002) Campylobacter surface-layers (S-layers) and immune evasion. Ann Periodontol 7:43-53

Toba T, Virkola R, Westerlund B, Bjorkman Y, Sillanpaa J, Vartio T, Kalkkinen N, Korhonen TK (1995) A collagen-binding S-layer protein in Lactobacillus crispatus. Appl Environ Microbiol 61:2467-2471

Turroni F, Serafini F, Foroni E, Duranti S, O'Connell Motherway M, Taverniti V, Mangifesta M, Milani C, Viappiani A, Roversi T, Sánchez B, Santoni A, Gioiosa L, Ferrarini A, Delledonne M, Margolles A, Piazza L, Palanza P, Bolchi A, Guglielmetti S, van Sinderen D, Ventura M (2013) Role of sortase-dependent pili of Bifidobacterium bifidum PRL2010 in modulating bacterium-host interactions. Proc Natl Acad Sci USA 110:11151-11156 
van Tassell ML, Miller MJ (2011) Lactobacillus adhesion to mucus. Nutrients 3:613-636

Velazquez L, Dussan J (2009) Biosorption and bioaccumulation of heavy metals on dead and living biomass of Bacillus sphaericus. J Hazard Mater 167:713-716

Wang B, Kraig E, Kolodrubetz D (2000) Use of defined mutants to assess the role of the Campylobacter rectus S-layer in bacteriumepithelial cell interactions. Infect Immun 68:1465-1473
Zhang W, Wang H, Liu J, Zhao Y, Gao K, Zhang J (2013) Adhesive ability means inhibition activities for Lactobacillus against pathogens and S-layer protein plays an important role in adhesion. Anaerobe 22:1-7 